\title{
FÓRUM do JOVEM PESQUISADOR
}

\author{
Sérgio Gabriel Silva de BARROS*
}

Caro leitor,

Ficamos encantados em retornar a Brasília em outubro de 2008, tanto pela receptividade dos brasilienses, quanto pela organização da VIII Semana Brasileira do Aparelho Digestivo.

Neste número dos ARQUIVOS de GASTROENTEROLOGIA convidamos nossos leitores a visitar os resumos das apresentações do excelente debate no Fórum "Educação Médica, Pesquisa e Pós-Graduação" daquela semana.

O professor Luiz Troncon, inicialmente, salientou a importância da Educação Médica Continuada (EMC), face ao crescente volume de novos conhecimentos que nos desafiam, buscando melhorar a assistência aos nossos pacientes. Luiz Troncon reflete, lucidamente, que a EMC precisa encontrar formas criativas para transmitir não só novas informações, mas também outras habilidades e reforçar atitudes frente ao novo conhecimento.

O professor Nicolau Czeczko, a seguir, ilustrou que a oferta de novos programas de Pós-Graduação (PG) no país aumentou em 100 x nos últimos 40 anos. Observou que o estudo permanente e a pesquisa é fundamental para qualquer profissional na sua prática. Entretanto, alertou os jovens médicos, que reflitam bem sobre o ingresso em cursos de Mestrado e/ou Doutorado, que demandam grande dedicação e recursos financeiros. Concluiu que esses cursos são apropriados para aqueles que têm vocação pelo ensino e pela pesquisa.

A professora Maria do Carmo Passos enfatizou a necessidade de educação permanente para todos e sobre a sua opção pela área acadêmica. Em agradável reflexão, discorreu sobre sua experiência na $\mathrm{PG}$, inicialmente no país e, posteriormente, nas universidades de Barcelona e Harvard. Salientou que há ótimas PGs no país e alerta os candidatos a PGs no exterior que reflitam bem

"aonde ir", "com quem trabalhar" e "como financiar" esse período.

"Last but not least", nosso caro colega Ricardo Viebig, com a sua experiência como editor dos ARQUIVOS, nos brinda com "dicas" para quem quer publicar suas teses, sua casuística ou mesmo relatos de casos interessantes em periódicos com melhor qualidade.

* Programa de Pós-graduação: Ciências em Gastroenterologia, Faculdade de Medicina, Universidade Federal do Rio Grande do Sul, Porto Alegre, RS 